\title{
Evaluation of the Mechanic and Electrochemical Properties of an Epoxy Coating with Addition of Different Polyhedral Oligomeric Silsesquioxanes (POSS) Applied on Substrate of Low Alloy Steel
}

\author{
Marielen Longhi ${ }^{a}$, Lucas Pandolphi Zini ${ }^{a}$, Vinícius Pistor ${ }^{b}$, Sandra Raquel Kunst ${ }^{a}$, Ademir José Zattera ${ }^{a}$ \\ ${ }^{a}$ Laboratório de Corrosão e Proteção Superficial - Pesquisa (LCOR-P), Universidade de Caxias do Sul, \\ 95070-560, Caxias do Sul, RS, Brazil. \\ ${ }^{b}$ Institute of Chemistry, Universidade Federal do Rio Grande do Sul, 90040-060, Porto Alegre, RS, \\ Brazil.
}

Received: November 29, 2016; Revised: June 06, 2017; Accepted: July 12, 2017

\begin{abstract}
The epoxy resin is one of the matrices most employed in obtaining composites and coatings. Its properties have been modified using materials such as clays and polyhedral oligomeric silsesquioxanes - POSS. The use of POSS in the preparation of thermosetting nanocomposites has been studied in obtaining hybrid materials with higher mechanic and surface properties. The functionality of POSS cage is important, since a thermosetting is formed by a cross-linked structure that can interact at any direction, forming bonds or acting in the interface of the cages inserted. This works aims to evaluate the influence of three POSS (Glycidylisobutyl-POSS, Triglycidylisobutyl-POSS and Glycidyl-POSS) added in epoxy resin, in the mechanic and electrochemical behaviors, when applied on low alloy steel. It was observed an increase in roughness and hydrophobicity. The sample containing Glycidylisobutyl-POSS presented the best results of corrosion resistance. Glycidyl-POSS showed an inefficient dispersion, forming agglomerates, leading to a low electrochemical behavior.
\end{abstract}

Keywords: POSS, epoxy resin, corrosion.

\section{Introduction}

The organic coatings were used, for a long time, only for improving the aesthetic appearance of the materials covered by them. The protection against corrosion became important with the introduction of paints and varnishes in North America and Europe, where the climatic conditions are more severe, mainly due to the low temperatures. From that moment, the paint formulations became more complex and, nowadays, the coatings are intended, in addition to beautify and protect substrates, to confer or enhance properties, such as slip-resistance, insulating, conducting and others ${ }^{1,2}$.

Historically, from the early $20^{\text {th }}$ century, there was a significant progress in technological innovation segment of organic coatings. This development is illustrated by the emergence of nitrocellulose-based coatings in 1920, synthetic resins replacing the vegetal and animal based resins in 1930, epoxy resins prepared from epichlorohydrin in 1927, epoxy resins based on bisphenol-A in $1936^{3-5}$ and, consequently, an improvement of the employees painting methods ${ }^{4,6,7}$.

The epoxy resin is one of the most used matrices in the production of coatings. It stands out in the group of thermosetting materials due to the properties as ease of processing, mechanic properties and thermal stability ${ }^{2,3,6-9}$. Among the main applications for epoxy resins, its main uses are in organic coatings ${ }^{1-3,5}$, polymeric composites, encapsulants and industrial adhesives ${ }^{6,7,10}$.

*e-mail: marielen_longhi@hotmail.com
However, properties as hardness, tensile strength and thermal resistance have been systematically modified by using different materials such as clays, halogenated compounds and, more recently, polyhedral oligomeric silsesquioxanes (POSS), applied in several polymeric matrices for improving corrosion resistance $e^{6,710}$.

The materials obtained after this step of modification are known as composites, or hybrid materials, constituting systems of two or more materials. The reinforcements (named dispersed phase) added to the matrix (named continuous phase) allow an increase of the mechanic resistance, electric insulating, heat resistance and dimensional stability of the resin, which degree of improving of the properties depends on the amount, disposition and type of the applied reinforcement ${ }^{8}$.

The hybrid materials combine, synergistically, physicochemical characteristics of its components, allowing the acquisition of new properties. This type of material can be classified into two types according to the chemical bonds between the inorganic and organic phases. Those that have Van der Wals or electrostatic bonds are classified in class I, whereas those with covalent bonds or ionic bonds are classified in class II. In this study the hybrid film is included in class II, because they present organic group directly attached to the silicon, in connection of the nonhydrolyzable Si-C type. The hybrids of this class exhibit greater thermal stability of the organic component when compared to class I hybrids ${ }^{11-14}$. 
The use of composite materials, due to significant results in terms of improved thermal, mechanic and electrical properties of materials, is rising to replace traditional materials, whose individual properties do not meet the growing demands of the markets as better performance, security, economy and durability required by the market ${ }^{8,9-11}$.

With the addition of POSS in the epoxy resin, there is an improvement in the mechanical properties of impact and flexural strength, as well as to achieve greater thermoxidation resistance and a significant increase in temperature values of glass transition of the material ${ }^{9-11,15}$.

Nanotechnology has brought innovation to the organic coatings formulation. Protective properties could be improved using low contents of fillers in polymeric resins. Some fillers promote the barrier effect on coatings, which may be applied on metallic surfaces, hampering the contact with the corrosive media, minimizing the corrosive process. The durability of the coating and efficiency of the protective process depend on the chemical nature, thickness of the applied layer, adhesive forces and permeability of electrolyte ${ }^{15}$.

Meanwhile, few studies explored the application of modified epoxy coatings with incorporation of POSS against corrosion on metallic substrates, in addition to the mechanisms that may be associated with the barrier property expected to arise with these coatings, due to its hybrid nature. In this sense, the aim of this work is to evaluate the influence of the addition of three different polyhedral oligomeric silsesquioxanes POSS (Glycidylisobutyl-POSS, Triglycidylisobutyl-POSS and Glycidyl-POSS) in epoxy resin, in the morphological, mechanic and electrochemical behaviors, when applied on low alloy steel.

\section{Materials and Methods}

\subsection{Samples}

The materials used in this research were: resin diglycidyl ether of bisphenol-A (DGEBA) - Araldite GY-260, crosslinking agent modified cycloaliphatic polyamine - Aradur 2963BR, both provided by Huntsman Advanced Materials. The polyhedral oligomeric silsesquioxanes GlycidylisobutylPOSS, Triglycidylisobutyl-POSS and Glycidyl-POSS were purchased from Hybrid Plastics ${ }^{\mathrm{TM}}$. For the application of the coating, panels of low alloy steel were used, with dimensions of $70 \mathrm{~mm} \times 120 \mathrm{~mm} \times 0,65 \mathrm{~mm}$.

The three different POSS were embedded in resin at a concentration of $5 \%(\mathrm{w} / \mathrm{w})$, in a beaker of $250 \mathrm{ml}$, immersed in an ice bath to control the temperature during the dispersion through sonication. It was used a sonicator Sonics Vibracells VC505, with amplitude of $40 \%$. The dispersion was performed during 15 minutes, making pauses of 5 minutes at each 3 minutes to avoid rough increases of temperature during sonication. The cross-linking agent was manually dispersed, with a glass rod, with induction time of 10 minutes.
Low alloy steel panels were used to applicate the coating. Before receive the epoxy/POSS coating, the panels were sanded with sandpapers of different granulometries (\#320, $\# 400$ and \#600). The application of the coatings was performed through dragging on the steel panels, with a bar applicator (PA-5556 Bar Film Applicator, from BYK Gardner). Then, the samples were cured at $140{ }^{\circ} \mathrm{C}$ for 1 hour.

The samples were identified according to Table 1 and Table 2. The name used for resin was the abbreviation of its chemical composition, and the POSS were sorted in accordance to their glycidyl groups functionality.

Table 1. Nomenclature of the samples components.

\begin{tabular}{cc}
\hline Type of POSS & Nomenclature \\
\hline Glycidylisobutyl-POSS & POSSmono \\
Triglycidylisobutyl-POSS & POSStri \\
Glycidyl-POSS & POSSocta \\
Type of resin & Nomenclature \\
Epoxy resin based on & DGEBA \\
Bisphenol-A & \\
\hline
\end{tabular}

Table 2. Components of each sample.

\begin{tabular}{lccc}
\hline Sample & Resin & POSS & Concentration \\
\hline DGEBA/ & Epoxy & $\begin{array}{c}\text { Glycidylisobutyl- } \\
\text { POSS }\end{array}$ & $5 \%(\mathrm{~m} / \mathrm{m})$ \\
DGEBA/ & Epoxy & $\begin{array}{c}\text { Triglycidylisobutyl- } \\
\text { POSStri }\end{array}$ & $5 \%(\mathrm{~m} / \mathrm{m})$ \\
DGEBA/ & & POSS & \\
POSSocta & Epoxy & Glycidyl-POSS & $5 \%(\mathrm{~m} / \mathrm{m})$ \\
DGEBA & Epoxy & - & - \\
\hline
\end{tabular}

\subsection{Transmission electron microscopy (TEM)}

An ultramicrotome RMC Poder Tome XL equipped with a diamond knife was used to cut the samples with a thickness of $50 \mathrm{~nm}$, with a speed of $0.3 \mathrm{~mm} / \mathrm{s}$, at room temperature. The sections were collected on copper grids of 300 mesh and evaluated through transmission electron microscopy (TEM).

\subsection{Scanning electron microscopy (MEV) / energy dispersive spectroscopy (EDS)}

The morphological characterization was performed through scanning electron microscopy (SEM) and energy dispersive spectroscopy (EDS), in an equipment JEOL JSM-6510LV, equipped with a spectrometer X-ray energy disperser. The samples were observed from top view for identifying the superficial morphology, and cross-section to observe the thicknesses of the coatings. Micrographs were collected after the electrochemical impedance spectroscopy to verify the effect of the corrosive media on the samples. 


\subsection{Profilometry}

An equipment Taylor Hobson, Talysurf FTS Intra 2, assisted by the software Ultra 5.23.12.97, was used to analyze the roughness profile. Data length of $20 \mathrm{~mm}$ and step of $0.05 \mathrm{~mm} / \mathrm{s}$.

\subsection{Contact angle}

The hydrophobicity of the samples was evaluated through contact angle measurements by the sessile drop method, using an equipment developed by the Research Laboratory in Chemistry of Materials (University of Caxias do Sul). The contact angle was determined using an image analysis software and the measurements were performed by the software Surftens 3.0.

\subsection{Open circuit potential (OCP)}

Open circuit potential measurements were performed adopting as electrolyte a $\mathrm{NaCl} 3.5 \%$ solution at room temperature $\left(\approx 21{ }^{\circ} \mathrm{C}\right)$ and natural aeration, employing a potentiostat IviumStat, from Ivium Technologies, controlled by the software IviumSoft. A two-electrode cell was used; the samples as working electrode and the saturated calomel electrode as reference electrode. The measurements were executed through 1 hour of immersion.

\subsection{Electrochemical impedance spectroscopy (EIS)}

The electrochemical impedance spectroscopy measurements were performed with a test area of $0.7 \mathrm{~cm}^{2}$. The electrolyte was a $\mathrm{NaCl} 3.5 \%$ solution. EIE data were obtained through a potentiostat Iviumstat, from Ivium Technologies, assisted by the software Iviumsoft. A three-electrode cell was used; the samples as working electrode, the saturated calomel electrode as reference electrode and platinum as auxiliary electrode. The frequency range was from $100 \mathrm{kHz}$ to $1 \mathrm{mHz}$ and the amplitude of sinusoidal perturbation about $10 \mathrm{mV}$ around the corrosion potential.

\subsection{Impact strength}

The test of impact strength of the organic coatings was performed according to the standard ASTM D2794-93, with an equipment Heavy-Duty Impact Tester, from BYK Gardner, using an impact force of $1 \mathrm{~kg} / 50 \mathrm{~cm}$.

\subsection{Adhesion}

The adhesion of the coating to the metallic substrate was evaluated following the method B of the standard ASTM D3359-09. Six horizontal and six vertical cuts were made, with spacing of $2 \mathrm{~mm}$ and angle of $90^{\circ}$ between them. A fibrous $3 \mathrm{M}$ Scotch tape was applied on the area and it was removed in a single motion, at an angle of $180^{\circ}$. The area was compared with the standard.

\subsection{Flexibility}

The flexibility test of the coating applied on steel was performed following the conical mandrel method, described in the standard ASTM D522-93a, using the equipment Gardner Conical Mandrel, from BYK Gardner. The coating flexibility was evaluated by the presence or absence of cracks and defects on the film after the test.

\section{Results and Discussion}

\subsection{TEM}

The Figure 1 presents TEM images for nanocomposites containing different types of POSS. The sample DGEBA/ POSSmono (Figure 1 (a)) showed particles dispersed in a spherical shape, between $5 \mathrm{~nm}-10 \mathrm{~nm}$ of diameter, while the sample DGEBA/POSStri (Figure 1 (b)) showed spherical particles with diameter varying between $20 \mathrm{~nm}$ $40 \mathrm{~nm}$, with a worse dispersion than DGEBA/POSSmono. The presence of spheres demonstrates the characteristic of stabilizing interface stresses that occur because of the chemical affinity difference with DGEBA ${ }^{10}$. This difference of affinity makes the POSS nanoparticles exhibit the amphiphilic behavior, which facilitates the formation of clusters and agglomerates ${ }^{16}$.

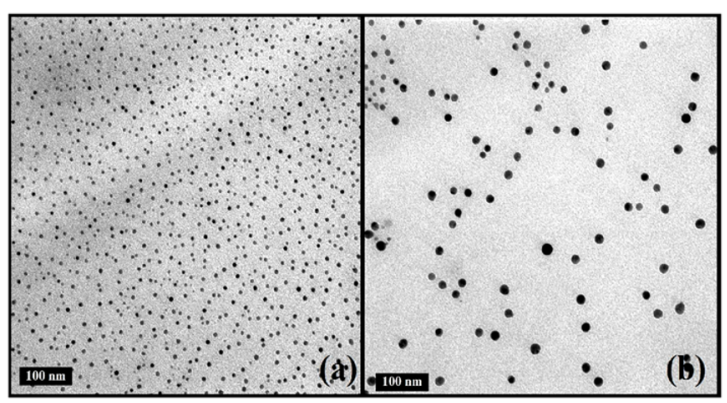

Figure 1. TEM analysis for the samples: (a) DGEBA/POSSmono, (b) DGEBA/POSStri.

Based on the assumption of formation of clusters, the spheres nucleus consists of the inorganic structure of the cages, while the organic groups capable of promoting interaction with the resin are positioned at the periphery of the spheres ${ }^{10,16}$. This behavior is only possible because during the curing period, the low resin viscosity facilitates the diffusion and formation of a rearrangement of POSS cages. Regarding the sample DGEBA/POSSmono, the sample DGEBA/POSStri showed wider spheres, possibly because the POSS with $\mathrm{n}=3$ presented more difficulty of packaging between the cages. The sample DGEBA/POSSocta, shown in Figure 2, at a magnification of $12000 x$, did not present 


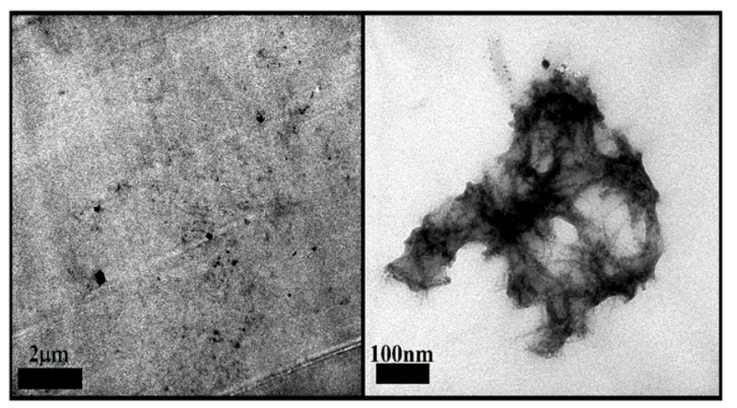

Figure 2. TEM analysis for the sample DGEBA/POSSocta.

an effectively dispersed phase and it was not evinced the formation of spheres that were observed in the samples DGEBA/POSSmono and DGEBA/POSStri.

At magnifications of $200000 x$, agglomerates formed between the cages of POSSocta and DGEBA were evinced. This formation probably occurred due to its high functionality that allows the formation of several side bonds during the curing process, and this restricted the cages distribution along the matrix ${ }^{17}$. The complexity of the structure may trigger different dispersion possibilities, and the interaction between the nanofiller and matrix basically depends on the specie and size of the involved organic group ${ }^{16}$. Generally, the clustering of POSS is noticed in form of clusters due to its amphiphilic character. In order to reach a thermodynamic equilibrium to offset the electrostatic forces of attraction and repulsion, the inorganic fraction agglomerates, forming these clusters.

The number of organic radicals possibly generated space restrictions, creating different clusters. For DGEBA/ POSSmono, clusters are uniformly formed and have a good dispersion, probably by the presence of only one organic group in each inorganic cage. So, the clusters formation is faster. The contrary occurs with the sample DGEBA/POSSocta, due to a higher concentration of glycidyl radicals, and the formation of dispersed and spherical clusters is compromised, leading to the appearance of lamellar structures ${ }^{10,16,18}$.

\section{$3.2 \mathrm{EDS}$}

Through EDS of the cross-section, a mapping of chemical compounds present in the coating was performed and the dispersion of POSS in the polymeric matrix was verified. The Figure 3 shows the points of higher concentration of silicon in the samples. It is observed in Figure 3 (a), which corresponds to the silicon mapping for the system DGEBA/POSSmono, a good distribution, presenting clusters well dispersed. The Figures 3 (b) and (c) show the silicon concentration for the systems DGEBA/POSStri and DGEBA/POSSocta. It is possible to see wider points of concentration for the sample containing POSStri, in addition to agglomerates in the sample containing POSSocta.

Comparing the TEM images, it can be observed coherence in results, since the clusters and agglomerates can be seen through the points of higher silicon concentration. According to TEM images (Figure 1 and Figure 2), the system containing POSSmono presents an efficient silicon dispersion in the matrix. In addition, the system POSStri presents wider silicon clusters than the sample DGEBA/POSSmono. Similarly, the system containing POSSocta shows silicon agglomerates even greater comparing to the other samples.

\subsection{Profilometry}

The surface roughness can be defined as a group of irregularities, mainly protrusions and recesses, which characterizes a particular surface. The average roughness ( $\mathrm{Ra}$ ) is calculated through the arithmetic average of the absolute values of the points heights that make up the profile, in relation to the midline. The midline is a reference line that divides the surface profile, so that the sum of the upper areas is equals to the sum of the down areas. This is the most commonly used parameter as indicator of surface roughness ${ }^{19,20}$.

The roughness profile $\mathrm{Ra}$ of the epoxy resin and its respective nanocomposites is shown in Figure 4. All the samples containg POSS, regarding the sample DGEBA, showed higher roughness; this result was expected because the addition of nanofillers, which modify the matrix. Conradi et al. highlight an increase of up to $40 \%$ in roughness and hardness of the material for adding silica nanoparticles in epoxy resin ${ }^{21}$. For Wang et al., the addition of methacrylisobutyl-POSS in dental resin promoted an increase of surface roughness of the hybrid material ${ }^{22}$.

It is also observed that the sample DGEBA/POSSmono exhibited a roughness significantly higher than the other samples, with Ra value of $0.2108 \mu \mathrm{m}$. This significant difference between the mean roughness of the samples can be associated to the homogeneity of the system containing POSSmono, which presented a good POSS dispersion in resin, as observed in TEM images, Figure 1 (a), and silicon mapping images, Figure 3 (a).

However, the sample containing POSSocta showed a roughness very close to the one found for the sample DGEBA, possibly because of the dispersion of POSSocta in the resin, as it can be observed in TEM images (Figure 2), as well as the silicon mapping shown by Figure 3 (c), which shows agglomerates of the component in the polymeric matrix.

\subsection{Contact angle}

The hydrophobicity is commonly evaluated by the contact angle that is formed in the interface between the liquid and a solid surface, since, in this phenomenon, the lower the contact angle, the higher the wettability and the solid has a character more hydrophilic. The hydrophobicity that a coating promotes indicates the capacity of anticorrosive protection, and it is proportional to the contact angle of the liquid with the solid surface. 

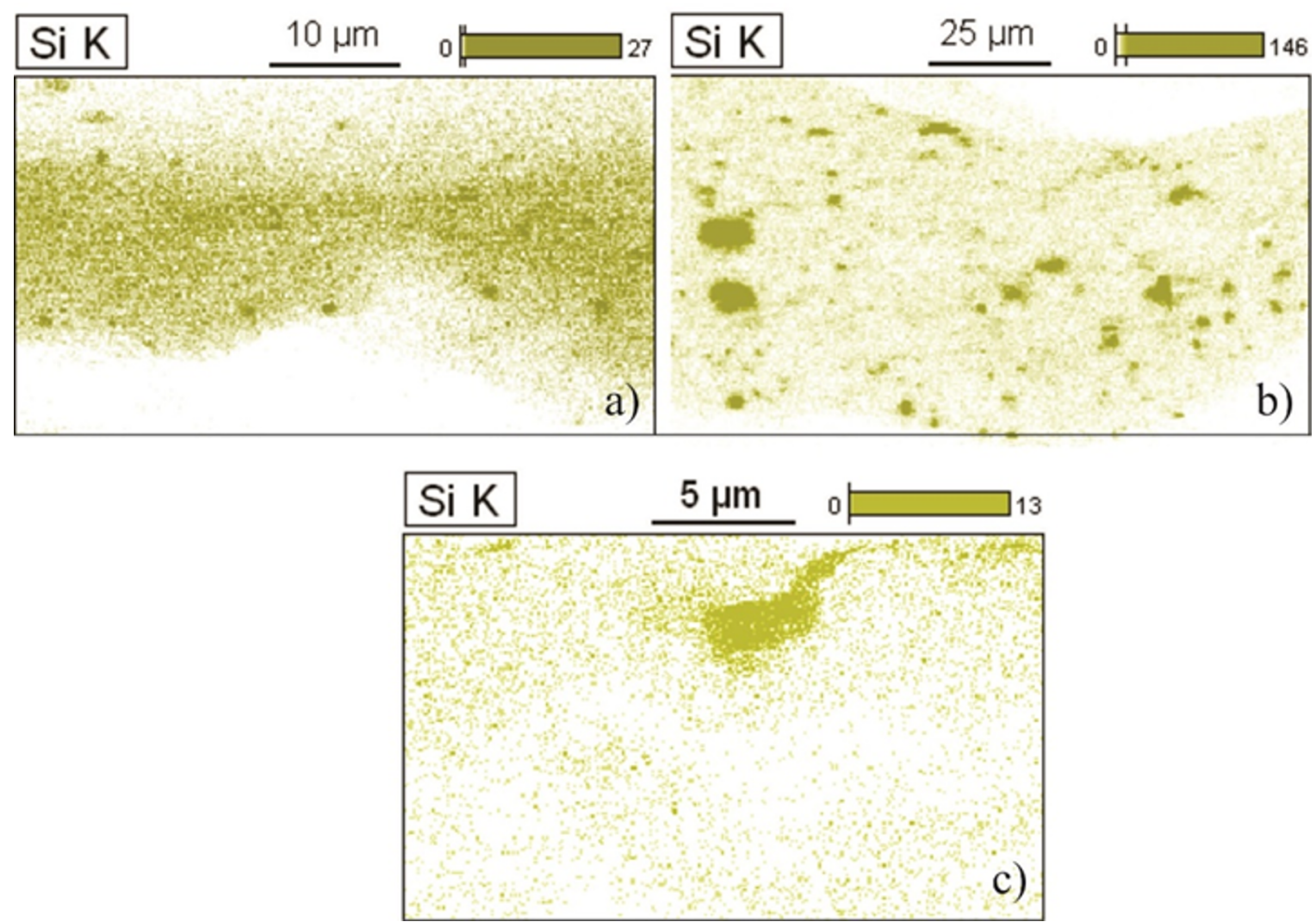

Figure 3. EDS mapping of silicone for the samples: (a)DGEBA/POSSmono, (b) DGEBA/POSStri and (c) DGEBA/POSSocta.

The Figure 5 shows a graph of the contact angle measurements and the standard deviations. The addition of POSSmono and POSStri increased the hydrophobicity of the coating in comparison to POSSocta and DGEBA. It was evinced a significant increase in the contact angle values for the system containing POSSmono, higher than $90^{\circ}$. On the other hand, the samples containing POSSocta presented contact angle values lower than $50^{\circ}$, showing a hydrophilic character of the coating.

This hydrophobicity shown by the sample containing POSSmono can be associated to the fine dispersion of POSSmono, which promotes the formation of a silicon barrier on the surface, as well as an increase of superficial tension, which makes the surface more hydrophobic than the other samples. Studies highlight that the incorporation of POSS in the epoxy resin increases the concentration of silicon on the coating surface, which favors a repulsive force of water, leaving the surface more hydrophobic when compared to the pure resin ${ }^{23,24}$.

The adsorption of water on a surface is caused by the equilibrium between adhesive and cohesive forces. As there is an increase in adhesive forces in comparison to the cohesive ones, the liquid increases it contact area with the substrate and the contact angle with the surface is smaller ${ }^{25}$.

The system containing POSSocta showed a more hydrophilic character because of the formation of agglomerates, which makes the coating more vulnerable to water absorption, once the free volume increases and an effective barrier system is not formed.

It is possible to relate the contact angle results with the surface roughness of the film, and the surface roughness directly influences the superficial tension, in addition to the coating chemical composition and the interaction with the water molecules.

POSSmono showed a higher roughness than the other systems, as it can be seen in Figure 4, corroborating with the literature that relates higher surface roughness with the more hydrophobic character. Ammar et al. point out that the incorporation $\mathrm{ZnO}$ nanoparticles in epoxy resin increases the composite surface roughness and, consequently, the hydrophobicity of the material ${ }^{26}$. Przadka et al. also obtained an increase of hydrophobicity using POSS, and they related it with the increase of surface roughness ${ }^{27}$.

Regarding the superficial tension, it is important to point out that the physical phenomenon that occurs in the formation of contact angle depends on the surface conditions, such as roughness and presence of impurities, in addition to the air layer that can modify the angle. Some authors indicated that the superficial tension results of a free energy for performing work on the surroundings, which can be associated with the surface atoms $\mathrm{s}^{24,28}$. 

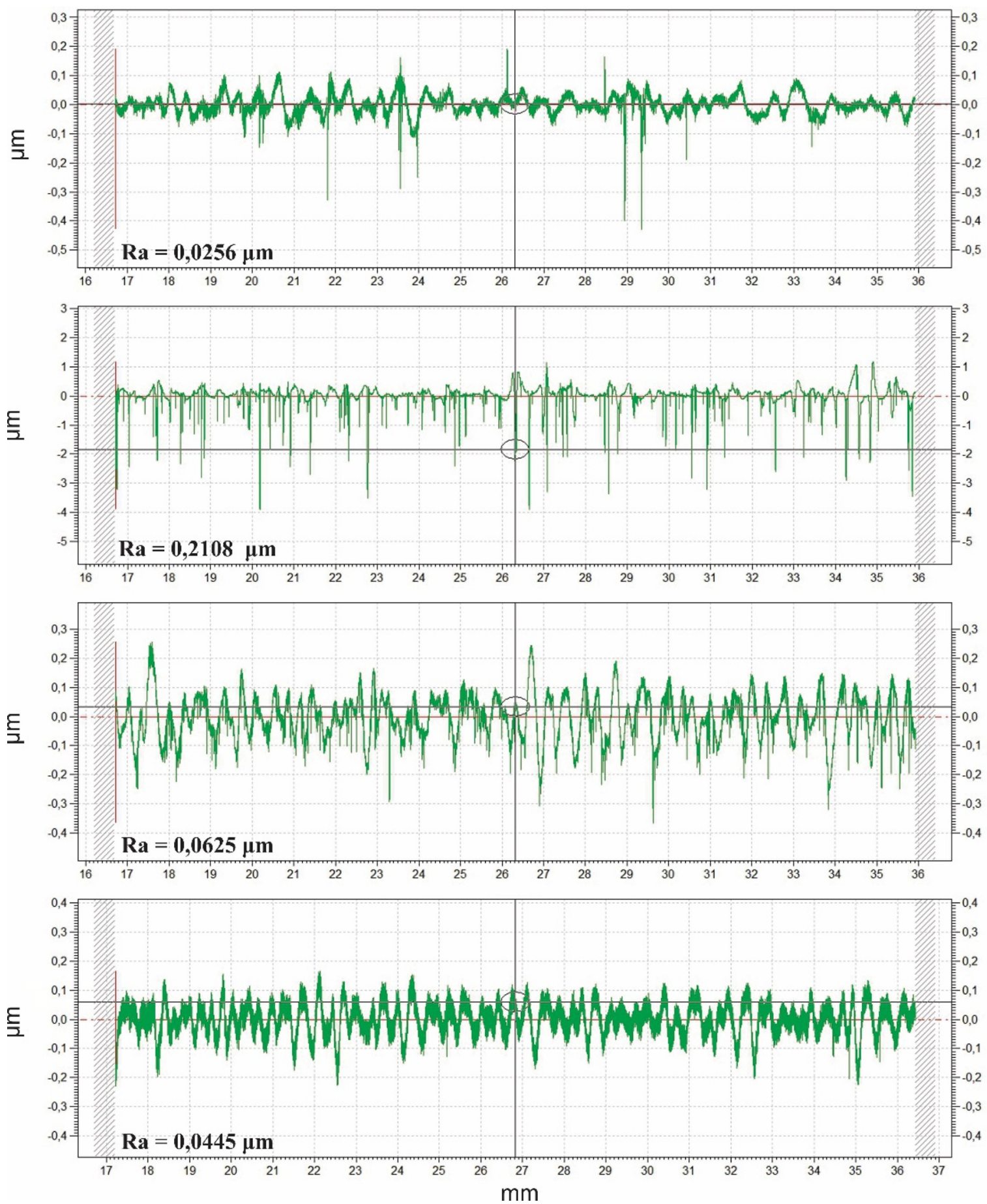

Figure 4. Roughness profile Ra of the samples: (a) DGEBA, (b) DGEBA/POSSmono, (c) DGEBA/POSStri and (d) DGEBA/POSSocta, applied on steel.

The authors Wang et al. pointed out as hydrophobic surfaces those that show regions of weak hydrogen bonds, thus having a cohesion force between the water molecules, which results in a weak adhesion of water on the substrate. In contrast, the hydrophilic surfaces have sites of hydrogen bonds with a high bond force, so that the adhesive force is greater than the cohesive force ${ }^{29}$.

\section{$3.5 O C P$}

The curves obtained with the open circuit monitoring are shown in Figure 6. It is observed at the first hours of immersion that the systems containing POSSmono and POSSocta demonstrated stable potentials and nobler than the other studied samples. This good performance of the sample DGEBA/POSSmono at the first hour of immersion can be 


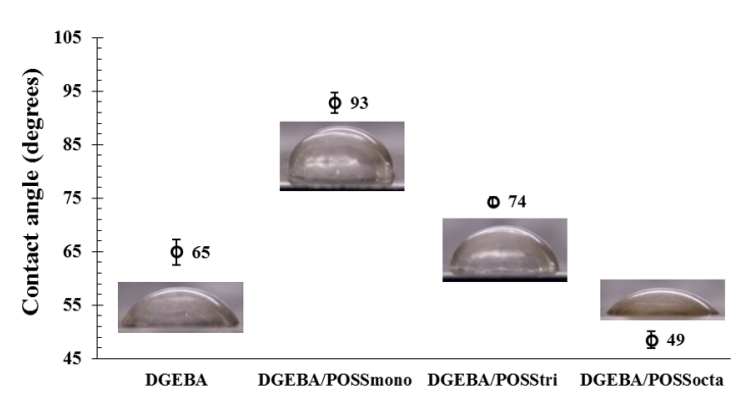

Figure 5. Contact angle values and standard deviations of the measurements.

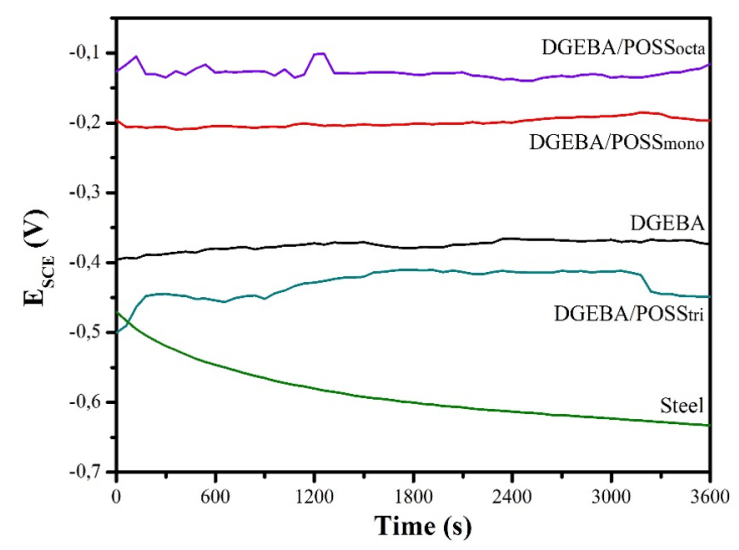

Figure 6. Open circuit potential curves for steel coated with epoxy resin and its respective composites and steel without coating.

associated to the POSS homogeneous dispersion, clusters well dispersed showing a good distribution. This fact can be visualized in the results obtained in the EDS and TEM analyzes. A similar behavior was observed for the system containing POSSocta and hypothetically is associated to the agglomerates that form a silicon barrier, in addition to the film hardness, which becomes it less permeable at the first hours. However, the samples containing POSStri showed potentials next to the sample DGEBA, demonstrating that the incorporation of trifunctional POSS did not influence in the barrier effect between the coating and the metal ${ }^{30,31}$.

The increase in the nanocomposites hardness is justified by some authors, due to the formation of cross-links with the polymer chains and the epoxy resin, the functionality of POSStri and POSSocta makes the chains mobility difficult, possibly presenting free spaces, as well as forming clusters which makes the film more rigid. This rigidity may possibly be associated with the epoxy resin chains movement to be restricted by the presence of the POSS nanocages, due to its functionality, leading to a higher resistance to deformation ${ }^{10,18,32,33}$.

This rigidity of the system containing POSStri is an aggravating factor for the low electrochemical resistance, when compared to the other systems studied, mainly in the first hours of contact with the electrolyte, since this coating facilitates the permeation of the electrolyte. The results obtained in the OCP analysis corroborate with the other results of contact angle that demonstrated a hydrophilic character for the system containing POSStri.

All the systems showed a stability of the potential values. For DGEBA, the potencial stabilized at approximately -0.4 $\mathrm{V}$; for DGEBA/POSSmono, the value remained constant at - $0.2 \mathrm{~V}$; DGEBA/POSStri showed a less noble potential, however also constant at $-0.45 \mathrm{~V}$. The system containing POSSocta had a constant potential at approximately -0.12 $\mathrm{V}$. All the samples exhibited higher potentials than steel without coating.

This fact occurs due to the presence of a barrier film between the electrolyte and the substrate, which hinder the corrosive action. Thus, at the fisrt hours of immersion, the electrolyte ions cannot permeate through the film, because of the high cross-link density ${ }^{31}$.

Meanwhile, there is a difference of approximately 0.2 $\mathrm{V}$ to $0.3 \mathrm{~V}$ between the system DGEBA and the systems containing POSSmono and POSSocta. This can be related to surface phenomena that happen on the coating, such as the formation of the electrical double layer and adsorption effects.

For the sample without coating, it is noticed that the potential values decrease along the immersion time. This occurs due to the absence of the barrier between the electrolyte and the substrate, thus leaving the metal susceptible to corrosion.

Most of metals present a thin oxide film on their surfaces and, when the metal is immersed in a corrosive solution, such as $\mathrm{NaCl} 3.5 \%$, it initially occurs the film dissolution. This step is generally accompanied by an accentuated variation in the corrosion potential, as it can be seen in the curve corresponding to steel in Figure 6. Firstly, the corrosion potential remains at a higher value and, after some time, it decreases to lower values. This decrease is attributed to the oxide film dissolution by the reductive dissolution process.

\subsection{EIS}

Generally, epoxy coatings, regarding the electrochemical impedance spectroscopy, exhibit a classic behavior, in other words, decrease of resistances in function of time, appearance of fragile points in the film, increase of capacitance due to water absorption and diagrams with various time constants when corrosion occurs on the metallic substrate.

The Figure 7 shows the Bode curves obtained through electrochemical impedance spectroscopy for 14 weeks of immersion. It is observed that the systems containing POSS demonstrated a level at high frequency associated to the barrier protection of the coatings.

However, the sample DGEBA showed a phenomenon at mean frequency, which is possibly associated to the permeability of the electrolyte into the film. The theta angle at $50^{\circ}$ indicates that the electrolyte has high permeability for a two-component epoxy system. These results are in accordance to which is observed in $\log Z$, since all the systems 


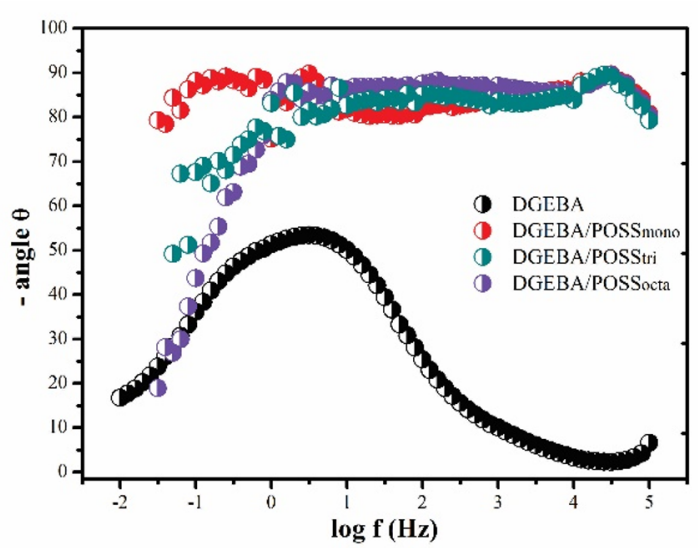

Figure 7. Bode curves of the samples immersed for 14 weeks.

containing POSS presented a resistance with magnitude around five times higher than the epoxy. This fact indicates a good performance of barrier protection of the coatings. Kumar and Sasikumar also obtained epoxy systems with incorporation of POSS with good immersion resistance in $\mathrm{NaCl} 3.5 \%{ }^{34}$. The authors associate the barrier effect to the cross-links between the resin and the POSS nanocages. The study of Markevicius et al. demonstrated good results with high corrosion resistance for polyurethane-based coatings with incorporation of POSS ${ }^{35}$.

After 18 weeks of immersion, the Bode curves are shown in Figure 8. The phenomena at high frequency remain for the samples DGEBA/POSSmono and DGEBA/ POSStri. However, for the system containing POSSocta, the phenomenon at high frequency disappears. Thus, the level associated with the barrier protection is not observed anymore and a phenomenon at medium frequency appears.

This phenomenon at medium frequency observed in DGEBA/POSSocta is possibly related to the electrolyte permeability, which indicates a system with low resistance to long periods. This result was already expected for the sample containing POSSocta, since this system showed an inefficient

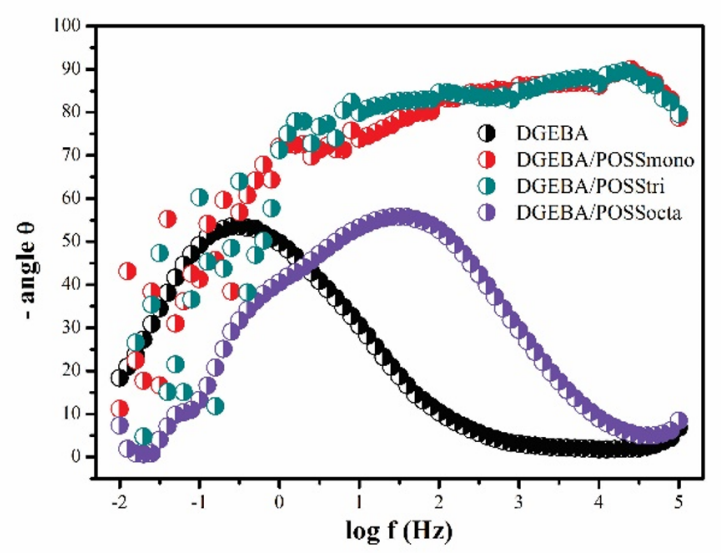

Figure 8. Bode curves of the samples immersed for 18 weeks.

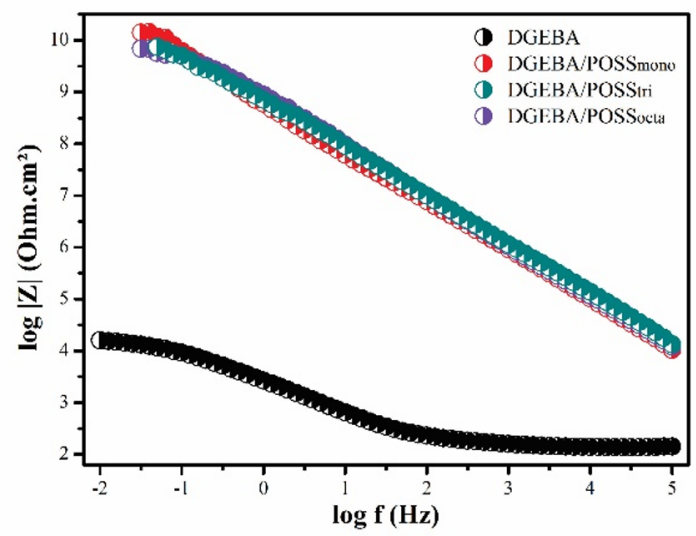

dispersion, with a larger free volume, as visualized in Figure 2 . In addition, the system had a character more hydrophilic among the samples, as the contact angle measurements demonstrate (Figure 5). Pistor associates the POSS high functionality to the low mobility of the nanocage, which possibly makes it harder to form a network of cross-links, hindering the formation of a structure with characteristics of barrier film ${ }^{17}$.

For the sample DGEBA, it was observed a displacement of the phenomenon that occurred on medium/low frequency. Hypothetically, this occurs because the system has cracks that allow charge transfer from metal into the medium.

In $\log \mathrm{Z}$ curve, the sum of the resistances for the DGEBA/ POSSmono and DGEBA/POSStri remains unchanged. These coatings have a good performance when compared with DGEBA/POSSocta, which showed similar results to DGEBA.

The Figure 9 shows the Bode curver after 20 weeks of immersion. The system containing POSSmono is the only system that still exhibits a level at high frequency, which can be associated to the coating barrier effect. The sample containing POSSocta shows two coupled phenomena, one at medium and one at low frequency at $\log \mathrm{f} \approx 2 \mathrm{~Hz}$.

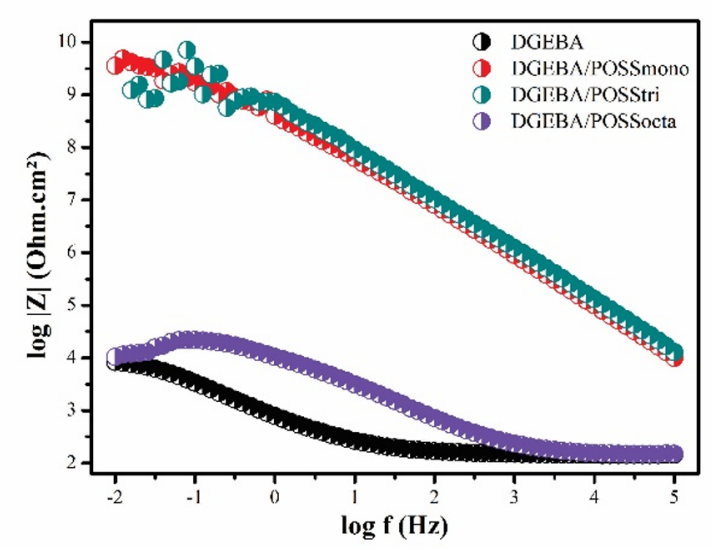




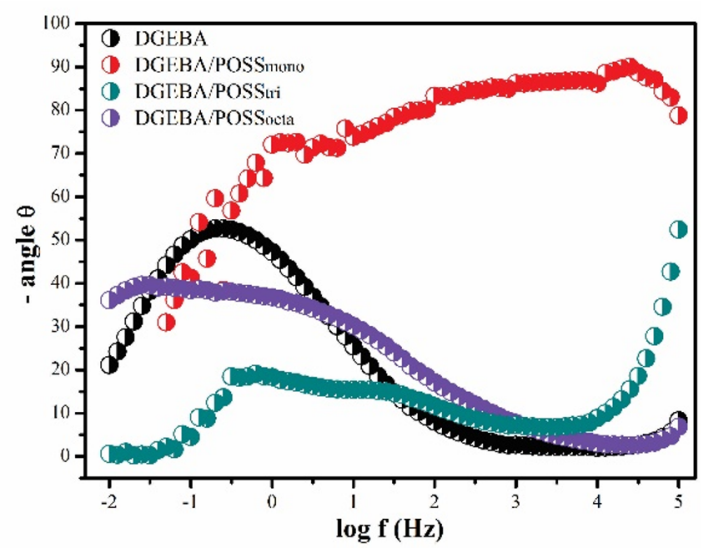

Figure 9. Bode curves of the samples during 20 weeks.

This result for the sample DGEBA/POSSmono confirms the results obtained in the contact angle measurements (Figure 5), whose system demonstrated the most hydrophobic character, in addition to the images obtained by TEM (Figure 1 (a)), which presents a POSSmono efficient dispersion in the matrix.

Among the samples containing POSS, DGEBA/ POSSocta was the first, followed by DGEBA, to permeate the electrolyte and be susceptible to the corrosion process. Hypothetically, the dispersion of POSS in the resin was one of the factors that facilitated the contact of the electrolyte with the substrate. The Figure 10 makes an analogy with the TEM images and illustrate the electrolyte permeation process in the coating. The Figure 10 (a) illustrates the process for DGEBA/POSSmono and Figure 10 (b) for DGEBA/POSS.

In the sample containing POSSmono and POSStri, the spheres homogeneously disposed in the epoxy resin hinder the water passage. Meanwhile, the agglomerates formed by the incorporation of POSSocta and the presence of free spaces facilitate the solution permeation.

Making an analogy with the use of pigments and the anticorrosive action in paints, the pigments with homogeneous disposition in the resin confer to the coating a higher water penetration resistance and, thus, promote a higher barrier protection, since the electrolyte passes for a long way to reach the substrate, as illustrated in Figure 10 (a).

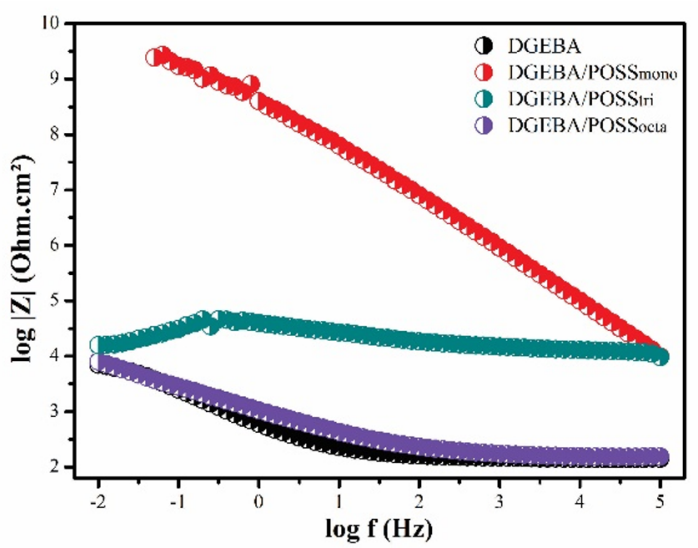

\section{7 SEM}

The Figures 11, 12, 13 and 14 show the images obtained from the samples after 22 weeks of immersion in a $\mathrm{NaCl} 3.5 \%$ solution, after the EIS tests, and the images obtained through scanning electron microscopy on three different points of the samples DGEBA, DGEBA/POSSmono, DGEBA/POSStri and DGEBA/POSSocta, respectively.

Visually, the four systems showed dark points with orange borders in points of direct contact with the electrolyte. On the region that was not in contact with the solution, no alteration was detected. For the samples DGEBA and DGEBA/POSSocta, corrosion of reddish color was observed, which is associated to the release of iron ions during the oxidation process.

By SEM images, it is possible to visualize, except in the system DGEBA/POSStri, the formation of corrosion products in an aggressive way, in the images obtained on the points in the area of direct contact with the electrolyte. A layer of crystals is formed on the substrate surface, possibly corrosion products such as metallic oxides and hydroxides. In the samples DGEBA and DGEBA/ POSSocta, it is noticed the formation of a thicker layer of corrosion products than the other samples. The sample DGEBA/POSStri does not show corrosion products in an aggressive way.
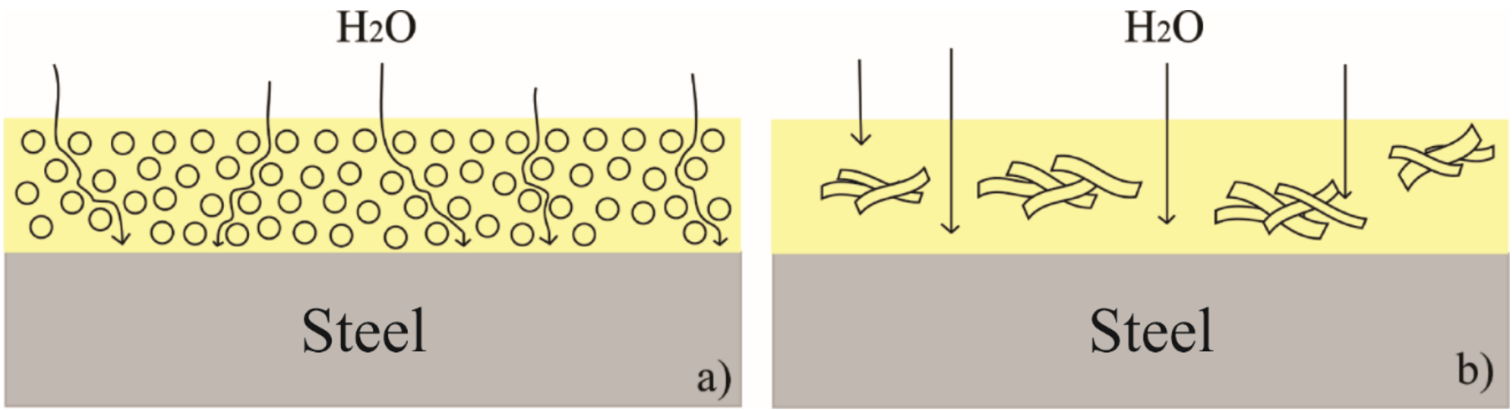

Figure 10. Schematic representation of the permeation of the electrolyte in the coatings: (a) DGEBA/POSSmono and (b) DGEBA/POSSocta. 


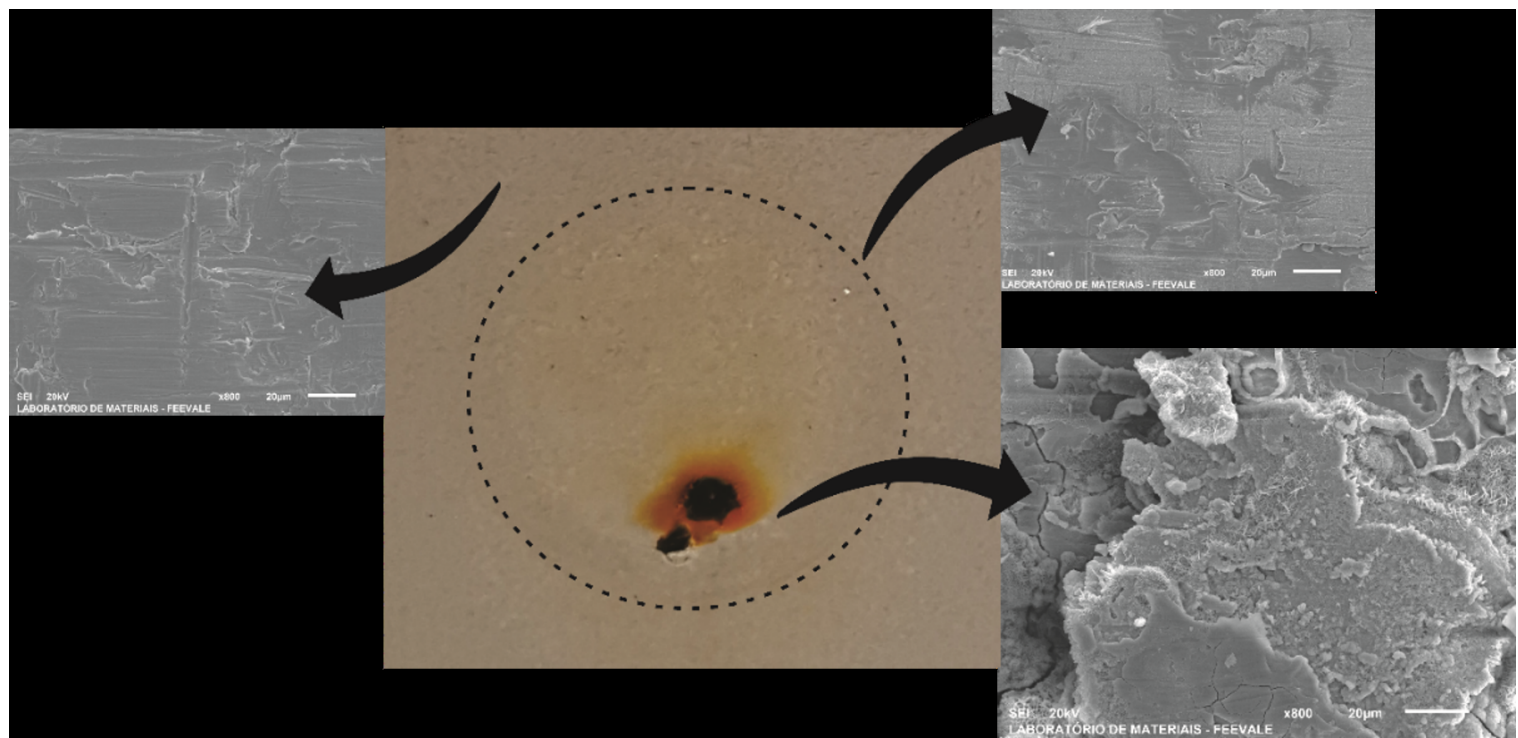

Figure 11. Images after EIS and SEM analysis on three different points of the sample DGEBA.

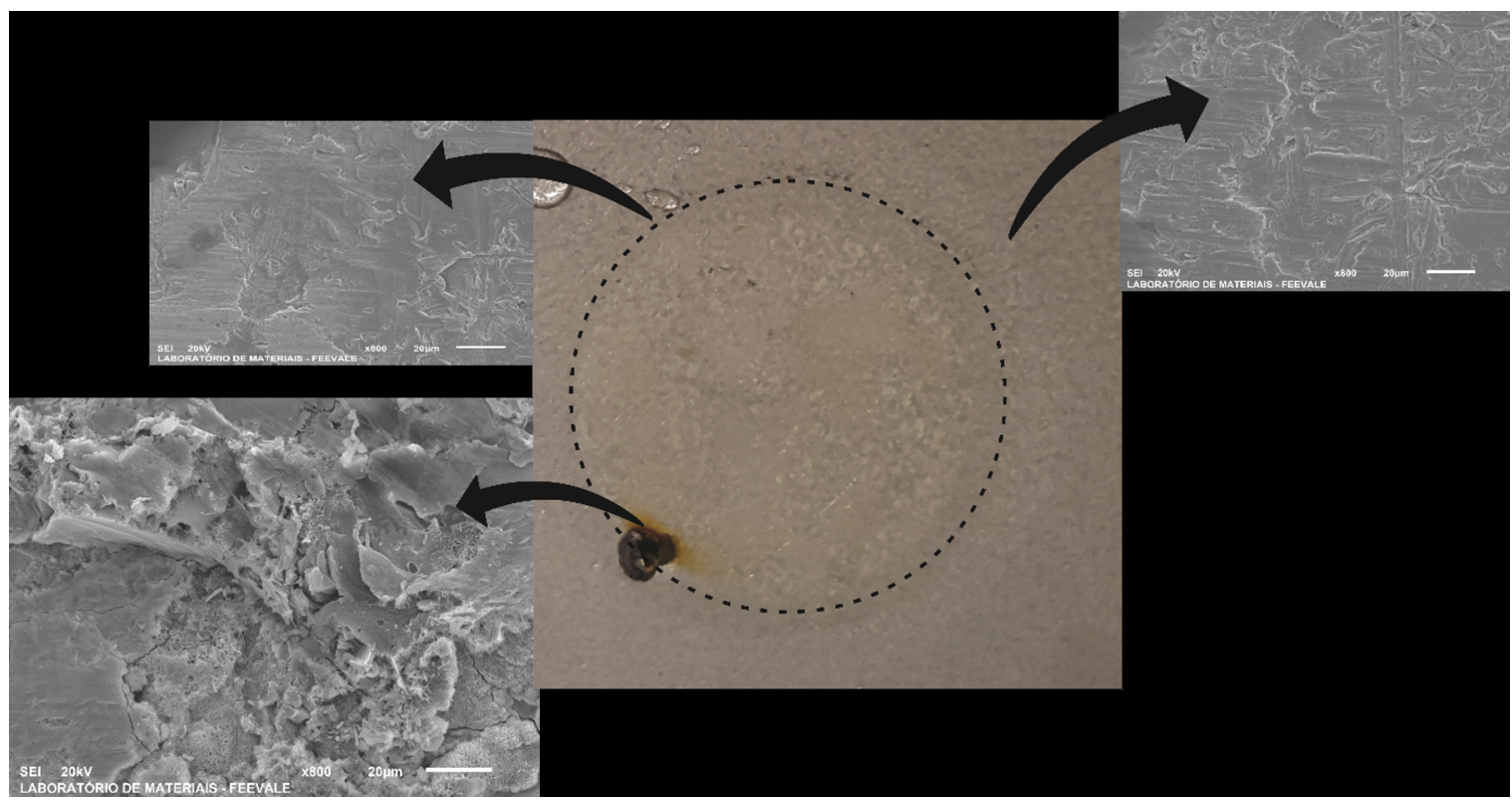

Figure 12. Images after EIS and SEM analysis on three different points of the sample DGEBA/POSSmono.

The formation of corrosion products with more intensity, in the samples DGEBA and DGEBA/POSSocta, confirms the results obtained in contact angle measurements. These systems had a more hydrophilic behavior and presented low resistance to long periods.

\subsection{Adhesion test}

The results of adhesion test of the coatings are shown in Figure 15. The samples DGEBA, DGEBA/POSSmono and DGEBA/POSSocta presented good adherence to the substrate and were classified as 5B, in accordance to ASTM D3359-09 ( $0 \%$ of peeling) In this sense, the addition of POSSocta and POSSmono did not change the characteristics of the coating.
However, the sample containing POSStri had a peeling of the film almost complete. The Figure 15 (c) shows the peeled area, highlighted with red lines. This sample was classified as $0 \mathrm{~B}$ (more than $65 \%$ of peeled grid area). Some authors point out that the increase of cross-link reactions reduce the reactivity of the components and, as result, the film becomes denser, which does not favor the adhesion with subsequent layers or the substrate ${ }^{36,37}$.

\subsection{Flexibility test}

Figure 16 (a) shows the images captured after the flexibility test for the sample DGEBA and Figure 16 (b) for the sample 


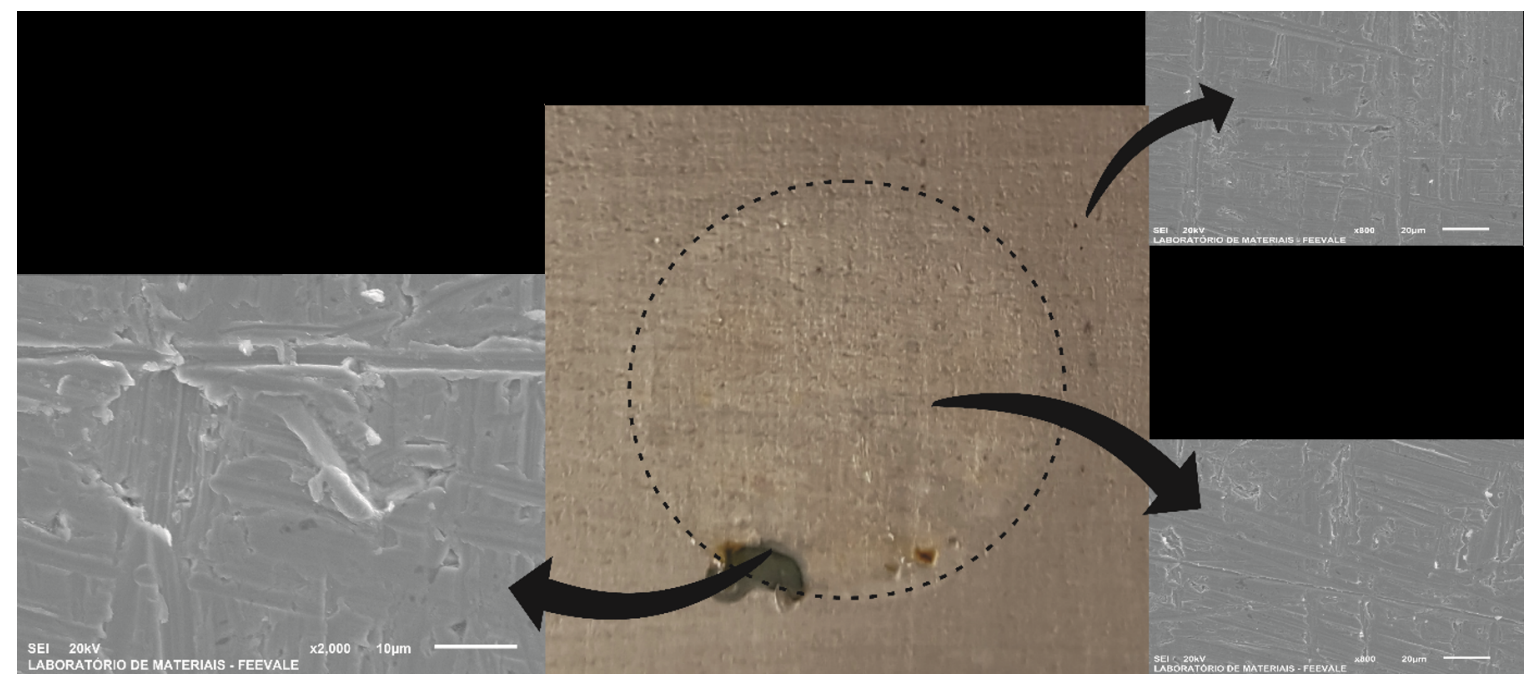

Figure 13. Images after EIS and SEM analysis on three different points of the sample DGEBA/POSStri.

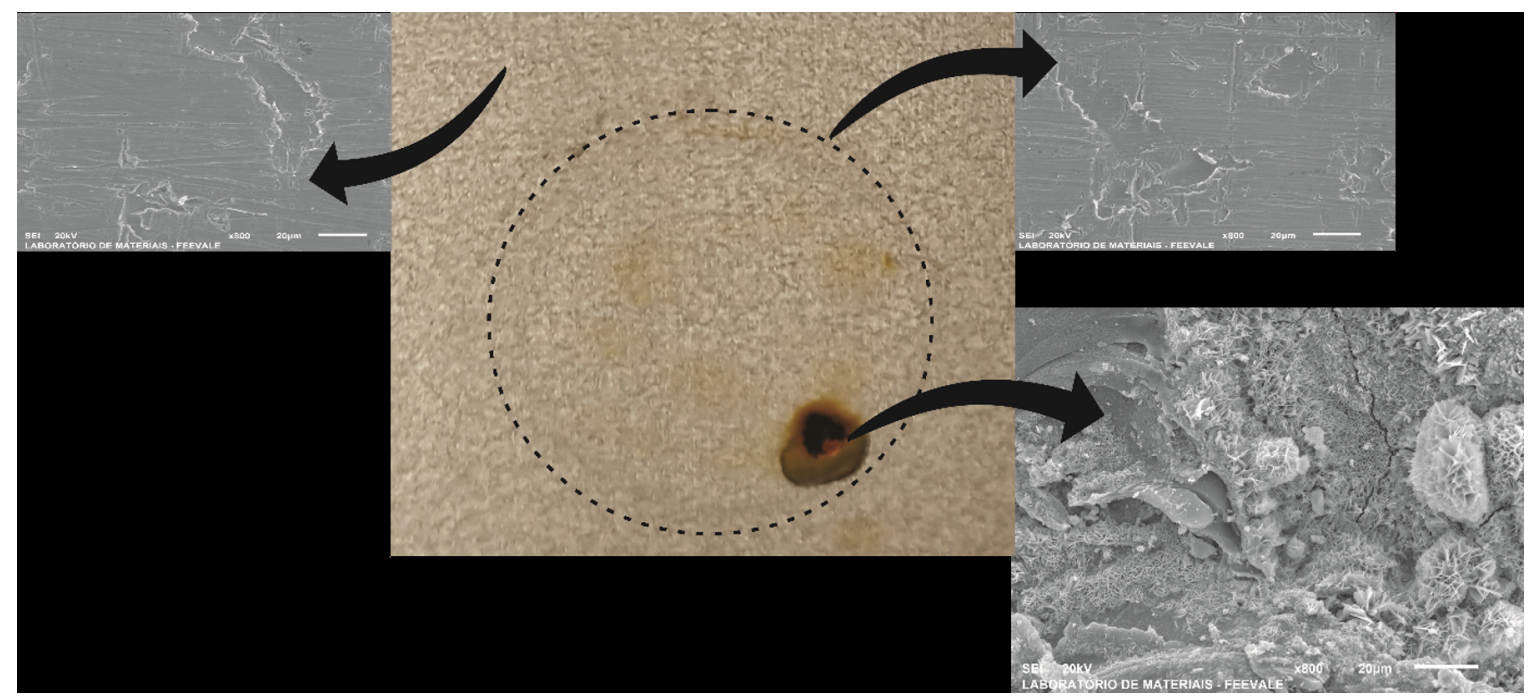

Figure 14. Images after EIS and SEM analysis on three different points of the sample DGEBA/POSSocta.

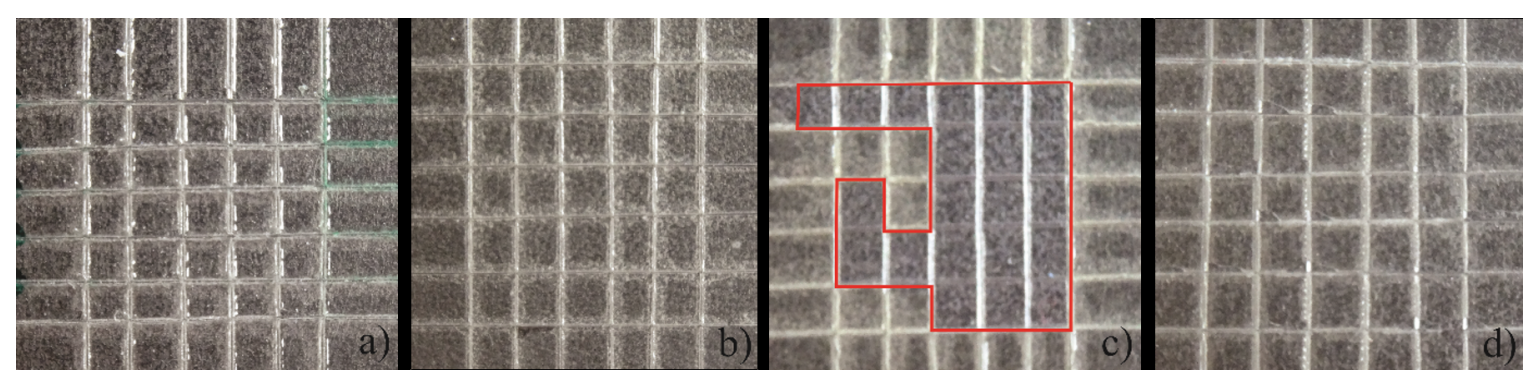

Figure 15. Adhesion test for the samples: (a)DGEBA, (b)DGEBA/POSSmono, (c)DGEBA/POSStri and (d)DGEBA/POSSocta applied on steel.

DGEBA/POSSmono, applied on steel. These samples are flexible, presenting just a little crack.

The Figure 17 (a) shows the images captured after the flexibility test for the sample DGEBA/POSStri and Figure 17 (b) for the sample DGEBA/POSSocta applied on steel. It is possible to observe that the sample containing POSSocta is the most cracked system. Cracks and almost complete peeling of the film were observed. These results show that possibly there is an increase in film hardness in accordance to the functionality of the POSS. Regarding the sample 


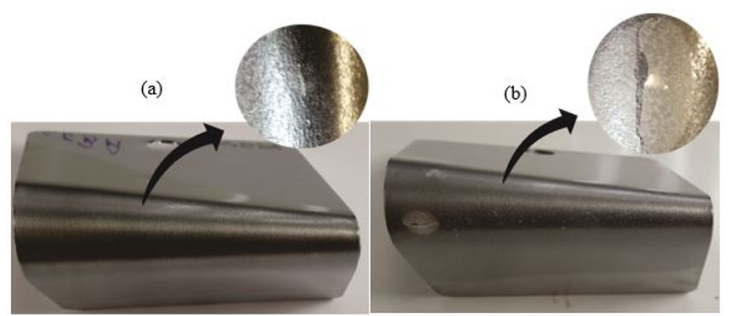

Figure 16. Flexibility test for (a) DGEBA and for the nanocomposite (b) DGEBA/POSSmono applied on steel.

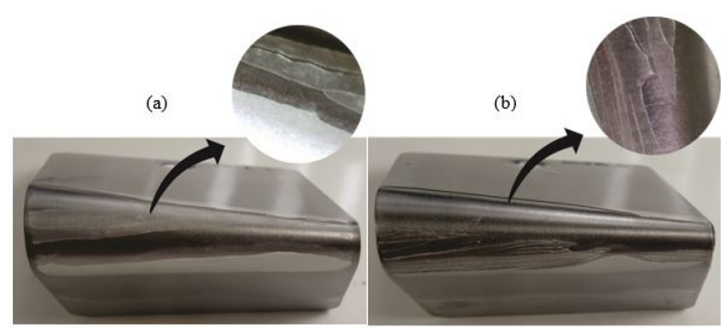

Figure 17. Flexibility test for (a) DGEBA/POSStri and for the nanocomposite (b) DGEBA/POSSocta applied on steel.

containing only resin, the addition of POSS makes the film less flexible.

According to Mirabedini and Kiamanesh, the addition of particles reduces the energy dissipation by the application of an external force, in addition to the possibility of forming agglomerates and the difficulty of dispersion ${ }^{38}$. This hardness increase of the system containing POSSocta can be related to the movement of the epoxy resin chains be restricted due to the presence of the POSSocta nanocages, and the formation of agglomerates, because of the high functionality, occasioning higher resistance to deformation and, consequently, higher hardness ${ }^{10,18,32}$.
Meanwhile, the system containing POSSmono is more flexible when compared to the sample containing POSSocta, due to the lower functionality, which promotes more mobility of the polymeric chains and, thus, an efficient dispersion, obtaining a more homogeneous film ${ }^{18,31,33}$.

\subsection{Impact strength}

The impact strength test qualitatively evaluated the behavior of the coatings in order to assess the visual appearance. All the steel panels presents peeling in the reverse application of force, while in the direct application some panels did not demonstrate cracks. The Figure 18 shows the images of the impact strength test for the samples containing only resin and the different types of POSS.

All the samples exhibited cracks where they were punctured, with detachment of the coating around. The panels with film containing POSSmono showed a wide affected region, as it can be observed in Figure 18 (b). Increasing the functionality of POSS from one to three, the coating proved to be less resistive, exhibiting a large detachment in the direct application of the force (Figure 18 (c)). However, for the coating containing POSSocta, it was observed a similar behavior to the pure resin, showing a less brittle coating, which was expected because of the flexibility results, since this coating was less flexible.

The performance presented by the substrate containing DGEBA/POSSmono shows that the nanocomposite has good resistance to forces of the flexible type, meanwhile it does not have a good behavior when submitted to impact forces. Hypothetically, this fact occurs due to the good flexibility, because the inverse occurs with the nanocomposite containing POSSocta, which demonstrates better impact resistance, due to the film hardness.

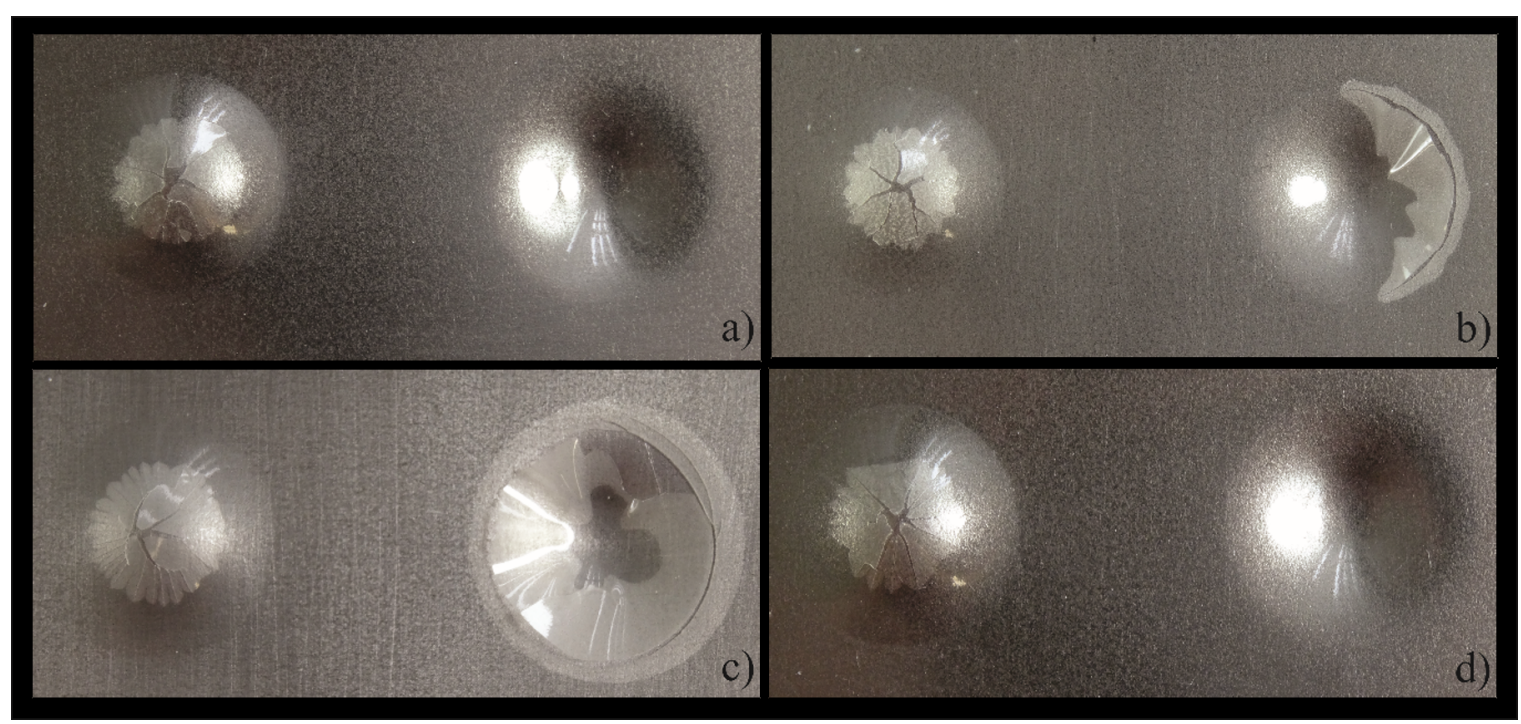

Figure 18. Impact strength for the samples: (a) DGEBA, (b) DGEBA/POSSmono, (c) DGEBA/POSStri and (d) DGEBA/POSSocta applied on steel. 
Some authors justify the enhancement of the mechanic properties due to the formation of cross-links with the epoxy resin polymeric chains. The high functionality of POSSocta does not facilitates the chains mobility, presenting free spaces, in addition to the formation of agglomerates, which makes the film more rigid ${ }^{10,18,32}$. Pistor et al. also point out that the increase of POSS concentration makes the nanocomposite less flexible ${ }^{10}$.

\section{Conclusions}

The addition of POSS to the epoxy resin promoted an enhancement of mechanic and electrochemical properties. The functionality of POSS also influenced in the nanocomposites behaviors.

TEM images showed that the dispersion of POSS was associated to the number of functional groups at the periphery of POSS cages. POSSmono presented efficient and homogeneous dispersion, but POSSocta formed agglomerates of lamellar structure.

The addition of POSS promoted an increase in the barrier protection of the coating, due to the higher crosslinks formation between the resin and POSS. The EIS measurements showed that the system containing POSSmono is the most resistant to corrosion, and the system DGEBA/ POSSocta is not resistive. DGEBA/POSSocta exhibited a more hydrophilic character compared to the other systems.

The mechanical properties of the coating applied on metallic substrate did not present enhancement with the addition of POSS. For impact strength tests, all the systems showed cracks in the application of the reverse force, in addition to the flexibility tests, where the samples containing POSS showed fissures and cracks.

\section{Acknowledgements}

The authors thank CAPES and CNPq for the financial support and University of Caxias do Sul (UCS) and University Feevale for the equipments used in this work.

\section{References}

1. Popov BN. Organic Coatings. In: Popov BN. Corrosion Engineering: Principles and Solved Problems. Cap. 13. Amsterdam: Elsevier; 2015. p. 557-579.

2. Esposito LH, Ramos JA, Kortaberria G. Dispersion of carbon nanotubes in nanostructured epoxy systems for coating application. Progress in Organic Coatings. 2014;77(9):1452-1458.

3. Hodgkin JH, Simon GP, Varley RJ. Thermoplastic toughening of epoxy resins: a critical review. Polymers for Advanced Technologies. 1998;9(1):3-10.

4. Jin FL, Li X, Park SJ. Synthesis and application of epoxy resins: A review. Journal of Industrial and Engineering Chemistry. 2015;29:1-11.
5. Paul S, ed. Surface Coatings: Science \& Technology. 2nd ed. Chichester: John Wiley \& Sons; 1996. 950 p.

6. Johnston K, Pavuluri SK, Leonard MT, Desmulliez MPY, Arrighi V. Microwave and thermal curing of an epoxy resin for microelectronic applications. Thermochimica Acta. 2015;616:100109.

7. Michels J, Widmann R, Czaderski C, Allahvirdizadeh R, Motavalli M. Glass transition evaluation of commercially available epoxy resins used for civil engineering applications. Composites Part B: Engineering. 2015;77:484-493.

8. Kannan RY, Salacinski HJ, Edirisinghe MJ, Hamilton G, Seifalian AM. Polyhedral oligomeric silsequioxane-polyurethane nanocomposite microvessels for an artificial capillary bed. Biomaterials. 2006;27(26):4618-4626.

9. Zhang Z, Gu A, Liang G, Ren P, Xie J, Wang X. Thermo-oxygen degradation mechanisms of POSS/epoxy nanocomposites. Polymer Degradation and Stability. 2007;92(11):1986-1993.

10. Pistor V, Puziski L, Zattera AJ. Influence of different concentrations of glycidylisobutyl-POSS on the glass transition of cured epoxy resin. Journal of Applied Polymer Science. 2014;132(7):41453.

11. Pistor V, Soares BG, Mauler RS. Influence of different concentrations of N-phenylaminopropyl - POSS on the thermodynamic fragility of the cured epoxy resin. Polymer. 2013;54(9):2292-2298.

12. Nassar EJ, Ávila LR, Pereira PFS, Nassor ECO, Cestari A, Ciuffi KJ, et al. Fenilsilicato dopado com Eu III obtido pelo método sol-gel. Química Nova. 2007;30(7):1567-1572.

13. Franken L, Santos LS, Caramão EB, Costa TMH, Benvenutti EV. Xerogel $p$-anisidinapropilsílica: estudo da estabilidade térmica e da resistência à lixiviação com solventes. Química Nova. 2002;25(4):563-566.

14. Carraro M, Gross S. Hybrid Materials Based on the Embedding of Organically Modified Transition Metal Oxoclusters or Polyoxometalates into Polymers for Functional Applications: A Review. Materials. 2014;7(5):3956-3989.

15. Fu JF, Shi LY, Yuan S, Zhong QD, Zhang DS, Chen Y, et al. Morphology, toughness mechanism, and thermal properties of hyperbranched epoxy modified diglycidyl ether of bisphenol A (DGEBA) interpenetrating polymer networks. Polymers for Advanced Technologies. 2008;19(11):1597-1607.

16. Strachota A, Whelan P, Kř́iž J, Brus J, Urbanová M, Šlouf M, et al. Formation of nanostructured epoxy networks containing polyhedral oligomeric silsesquioxane (POSS) blocks. Polymer. 2007;48(11):3041-3058.

17. Pistor V, Ornaghi FG, Ornaghi HL, Zattera AJ. Dynamic mechanical characterization of epoxy/epoxycyclohexyl-POSS nanocomposites. Materials Science and Engineering: $A$. 2012;532:339-345.

18. Pistor V, Puziski L, Zattera AJ. Effect of glycidylisobutylPOSS on the thermal degradation of the epoxy resin. Journal of Materials Science. 2015;50(10):3697-3705.

19. Gadelmawla ES, Koura MM, Maksoud TMA, Elewa IM, Soliman HH. Roughness Parameters. Journal of Materials Processing Technology. 2002;123(1):133-145. 
20. Parra BS, Gennari RC, Melchiades FG, Boschi AO. Rugosidade Superficial de Revestimentos Cerâmicos. Cerâmica Industrial. 2006;11(2):15-18.

21. Conradi M, Kocijan A, Kek-Merl D, Zorko M, Verpoest I. Mechanical and anticorrosion properties of nanosilica-filled epoxy-resin composite coatings. Applied Surface Science. 2014;292:432-437.

22. Wang W, Sun X, Huang L, Gao Y, Ban J, Shen L, et al. Structureproperty relationships in hybrid dental nanocomposite resins containing monofunctional and multifunctional polyhedral oligomeric silsesquioxanes. International Journal of Nanomedicine. 2014;9:841-852.

23. Zeng K, Wang L, Zheng S. Nanostructures and surface hydrophobicity of epoxy thermosets containing hepta(3,3,3trifluropropyl) polyhedral oligomeric silsesquioxane-capped poly(hydroxyether of bisphenol A) telechelics. Journal of Colloid and Interface Science. 2011;363(1):250-260.

24. Zucchi IA, Galante MJ, Williams RJJ. Surface energies of linear and cross-linked polymers based on isobornyl methacrylate and methacryl-heptaisobutyl POSS. European Polymer Journal. 2009;45(2):325-331.

25. Oberli L, Caruso D, Hall C, Fabretto M, Murphy PJ, Evans D. Condensation and freezing of droplets on superhydrophobic surfaces. Advances in Colloid and Interface Science. 2014;210:4757.

26. Ammar S, Ramesh K, Vengadaesvaran B, Ramesh S, Arof AK. Amelioration of anticorrosion and hydrophobic properties of epoxy/PDMS composite coatings containing nano $\mathrm{ZnO}$ particles. Progress in Organic Coatings. 2016;92:54-65.

27. Prządka D, Marcinkowska A, Andrzejewska E. POSS-modified UV-curable coatings with improved scratch hardness and hydrophobicity. Progress in Organic Coatings. 2016;100:165172.

28. Wu S. Calculation of interfacial tension in polymer systems. Journal of Polymer Science: Polymer Symposia. 1971;34(1):1930 .
29. Wang J, Li A, Chen H, Chen D. Synthesis of Biomimetic Superhydrophobic Surface through Electrochemical Deposition on Porous Alumina. Journal of Bionic Engineering. 2011;8(2):122-128.

30. Cardoso WS, Gushikem Y. Preparação de compostos lamelares: síntese do hidrogenofosfato de zircônio cristalino e sua intercalação com aminas. Um experimento para estudantes de graduação. Química Nova. 2005;28(4):723-726.

31. Pérez C, Collazo A, Izquierdo M, Merino P, Nóvoa XR. Characterisation of the barrier properties of different paint systems. Part II. Non-ideal diffusion and water uptake kinetics. Progress in Organic Coatings. 1999;37(3-4):169-177.

32. Ghermezcheshme H, Mohseni M, Yahyaei H. Use of nanoindentaion and nanoscratch experiments to reveal the mechanical behavior of POSS containing polyurethane nanocomposite coatings: The role of functionality. Tribology International. 2015;88:66-75.

33. Ragosta G, Musto P, Abbate M, Scarinzi G. Reactivity, viscoelastic behaviour and mechanical performances of hybrid systems based on epoxy resins and reactive polyhedral oligosilsesquioxanes. Polymer. 2009;50(23):5518-5532.

34. Kumar SA, Sasikumar A. Studies on novel silicone/phosphorus/ sulphur containing nano-hybrid epoxy anticorrosive and antifouling coatings. Progress in Organic Coatings. 2010;68(3):189-200.

35. Markevicius G, Chaudhuri S, Bajracharya C, Rastogi R, Xiao J, Burnett C, et al. Polyoligomeric silsesquioxane (POSS)hydrogenated polybutadiene polyurethane coatings for corrosion inhibition of AA2024. Progress in Organic Coatings. 2012;75(4):319-327.

36. van Ooij WJ, Zhu D. Eletrochemical Impedance Spectroscopy of Bis-[Triethoxysiliypropyl]Tetrasulfide on AA2024-T3 Substrates. Corrosion Science. 2001;57(5):413-427.

37. Romano AP, Fedel M, Deflorian F, Olivier MG. Silane sol-gel film as pretreatment for improvement of barrier properties and filiform corrosion resistance of 6016 aluminum alloy covered by cataphoretic coating. Progress in Organic Coatings. 2011;72(4):695-702.

38. Mirabedini SM, Kiamanesh A. The effect of micro and nanosized particles on mechanical and adhesion properties of a clear polyester powder coating. Progress in Organic Coatings. 2013;76(11):1625-1632. 